Anne Andriane, Erhamwilda / Ta'dib: Jurnal Pendidikan Islam, Vol. 9 No. 1 (2020) 42-50

ISSN 1411-8173 | E-ISSN 2528-5092

https:/ / ejournal.unisba.ac.id/index.php/tadib/article/view/6207

\title{
THE CORRELATION BETWEEN THE HABIT OF CARRYING OUT JAMAAH PRAYERS WITH THE DISCIPLINE ATTITUDE OF STUDENTS
}

\author{
${ }^{1}$ Anne Andriane, ${ }^{2}$ Erhamwilda \\ 1,2Program Studi Pendidikan Agama Islam Universitas Islam Bandung \\ Email: ${ }^{1}$ andriaanne98@gmail.com, 2erham_wilda@yahoo.co.id \\ DOI: https://doi.org/10.29313/tjpi.v9i1.6207 \\ Submitted: May 29th, 2020. Approved: June 20th, 2020. Published: June 20th, 2020
}

\begin{abstract}
Salat is an obligation for every Muslim. Prayer in congregation is rewarded by Allah Almighty twenty seven times higher than prayer alone. With regular prayer in congregation one will get used to the discipline of managing time. This study aims to determine whether there is a correlation between the habits of students praying in congregation with the attitude of student discipline. The study was conducted with a quantitative approach, descriptive method, and the type of correlation research. This research was conducted on eighth grade students in one Islamic junior high school in the city of Bandung. The study population was 8th grade students totaling 294 students. Samples were taken with a random sampling technique of 114 students. Hypothesis testing is done by 5\% error significance. Data collection research instruments include: Likert scale, questionnaires, documentation, interviews, and observations. Presentation of data uses frequency distribution, unit analysis, statistics, normality test, validity test, reliability test, correlation, and hypothesis test summary. The results of this study indicate that there is a significant positive correlation between the babit of carrying out congregational prayers with the discipline of students. It was concluded that to improve student discipline could be done by praying in congregation.
\end{abstract}

Keywords: Habits; Jamaah Prayer; Attitude of Discipline.

\begin{abstract}
Abstrak
Shalat merupakan kewajiban bagi setiap Muslim. Sholat berjamaah diberi ganjaran pabala oleh Allah Swt dua puluh tujuh kali lebih tinggi dari sholat sendirian. Dengan rutin sholat berjamaah seorang akan terbiasa dengan disiplin mengatur waktu. Penelitian ini bertujuan untuk mengetahui apakah terdapat korelasi antara kebiasaan siswa sholat berjamaah dengan sikap disiplin siwa. Penelitian dilakukan dengan pendekatan kuantitatif, metoda deskriptif, dan jenis penelitiannya korelasi. Penelitian ini dilakukan pada siswa kelas VIII di salah satu SMP Islam di Kota Bandung. Populasi penelitian adalah siswa kelas 8 yang berjumlah 294 siswa, Sampel diambil dengan teknik random sampling sebanyak 114 siswa. Uji hipotesis dilakukan dengan signifikasi kesalaban 5\%. Instrumen penelitian pengumpul data meliputi: skala likert, angket, dokumentasi, wawancara, dan observasi. Penyajian data menggunakan distribusi frekuensi, analisis unit, statistik, uji normalitas, uji validitas, uji reliabilitas, korelasi, dan ringkasan uji bipotesis. Hasil penelitian ini menunjukkan terdapat bubungan korelasi positif yang signifikan antara kebiasaan melaksanakan shalat berjamaah dengan sikap disiplin siswa. Disimpulkan untuk meningkatkan disiplin siswa dapat dilakukan dengan pembiasaan sholat berjamaah.
\end{abstract}

Kata Kunci: Kebiasaan; Shalat Berjamaab; Sikap Disiplin. 


\section{PENDAHULUAN}

Salah satu ibadah yang tidak boleh ditinggalkan oleh umat muslim adalah shalat. Shalat menurut bahasa mengandung dua pengertian, yaitu berdo'a dan bershalawat. Yang dimaksud di sini adalah berdo'a memohon hal-hal yang baik, nikmat dan rezeki. Sedangkan bershalawat adalah meminta keselamatan, kedamaian, keamanan, dan kelimpahan rahmat Allah Subhana wa Ta'ala. Kemudian secara istilah, shalat adalah pernyataan bakti dan memuliakan Allah dengan gerakan badan dan perkataan-perkataan tertentu yang dimulai dengan takbir dan diakhiri dengan salam yang dilakukan pada waktu-waktu tertentu setelah memenuhi syarat-syaratnya (Raya, Thib, \& Mulia, 2003, hal. 174). Adapun dasar kewajiban shalat terdapat dalam firman Allah Subhana wa Ta'ala dalam Q.S. An-Nisa ayat 103 yang artinya:

"Maka apabila kamu telab menyelesaikan shalat(mu), ingatlah Allah di waktu berdiri, di waktu duduk dan di waktu berbaring. Kemudian apabila kamu telab merasa aman, maka dirikanlah shalat itu (sebagaimana biasa). Sesunggubnya shalat itu adalah fardhu yang ditentukan waktunya atas orang-orang yang beriman".

Kemudian pelaksanaan shalat akan berpengaruh pada akhlak seorang muslim agar terjaga dari perbuatan keji dan munkar, seperti yang tercantum dalam firman Allah Subhana wa Ta'ala dalam Q.S. Al-Ankabut ayat 45 yang artinya:

Artinya: "Bacalah apa yang telah diwabyukan kepadamu, yaitu Al Kitab (Al Quran) dan dirikanlah shalat. Sesunggubnya shalat itu mencegah dari (perbuatan-perbuatan) keji dan mungkar. Dan sesunggubnya mengingat Allah (shalat) adalab lebih besar (keutamaannya dari ibadah-ibadah yang lain). Dan Allab mengetahui apa yang kamu kerjakan”.

Shalat berjamaah merupakan shalat yang dikerjakan bersama-sama oleh mukmin dan pahalanya lebih besar daripada shalat yang dikerjakan secara sendiri-sendiri, oleh karena itu shalat berjamaah lebih diutamakan. Shalat berjamaah kedudukannya dalam agama Islam menempati tempat utama, orang Islam yang mengerjakannya secara istiqamah akan mendapatkan tempat yang mulia. Islam memasukkannya ke dalam ibadah yang penuh tantangan dan ujian, pahala yang dijanjikan adalah sebanyak dua puluh tujuh derajat (tingkatan). Sabda Rasulullah yang artinya: "Dari Abdullah bin Umar, bahwasannya Rasul telah bersabda: Shalat berjamaah lebih utama dua puluh tujuh derajat daripada shalat sendirisendiri" (HR. Muttafaqun 'alaih atau Bukhari Muslim) (Masyhur, 1995, hal. 329).

Dalam shalat berjamaah, tampak sekali nilai-nilai sosial atau kebersamaan. Shalat yang dilakukan berjamaah juga mempunyai efek terapi kelompok (group therapy) sehingga menumbuhkan sikap disiplin, rasa kebersamaan, menghilangkan rasa cemas, dan terasingkan (Haryanto, 2009, hal. 132). Hal ini sangat penting sekali untuk ditumbuhkan dalam lingkungan, baik itu di lingkungan masyarakat, keluarga, maupun di lingkungan sekolah. Selain terdapat nilai pembentuk kedisiplinan dan kebersamaan, shalat yang dilakukan secara berjamaah juga senantiasa mengajarkan kepada umat Islam untuk disiplin, taat pada waktu, sekaligus menghargai waktu itu sendiri dan kerja keras. Masih banyak lagi keutamaan yang terkandung dalam shalat berjamaah.

Shalat berjamaah merupakan kegiatan rutin yang dilakukan oleh seluruh siswa-siswi di salah satu SMP di kota Bandung, kegiatan ini merupakan tata tertib sekolah. Tujuan diadakan shalat berjamaah ini adalah untuk menciptakan siswa-siswi yang senantiasa tepat waktu dan berjamaah dalam melaksanakan shalat. Melaksanakan shalat berjamaah secara 
rutin, diprediksi akan menumbuhkan sikap disiplin dalam diri siswa, baik disiplin dalam beribadah, disiplin waktu, disiplin dalam mentaati peraturan sekolah, maupun disiplin dalam belajar. Sehingga para siswa akan melakukan semua aturan atau tata tertib berdasarkan kesadaran sendiri atau tidak ada paksaan dari luar.

Kenyataan di lapangan masih banyak siswa yang bermalas-malasan dalam mengerjakan shalat berjamaah. Siswa harus diperintah terlebih dahulu oleh guru saat waktu shalat telah tiba, terutama shalat dhuhur dan shalat ashar (Observasi, 15 September 2018). Di sisi lain juga masih terjadi berbagai bentuk pelanggaran disiplin antara lain: telat datang ke sekolah, memakai seragam dengan atribut yang tidak lengkap, banyak izin ketika proses pembelajaran sedang berlangsung, gaduh ketika di dalam kelas, dan tugas sekolah yang tidak sepenuhnya dikerjakan. Mereka mengikuti aturan secara terpaksa, belum ada kesadaran (Observasi dan wawancara, 22 November 2018). Muncul pertanyaan, apakah mereka yang cenderung melanggar aturan ini termasuk yang terbiasa sholat berjamaah, atau mereka hanya sholat berjamaah di sekolah saja, apakah tidak ada hubungan antara kebiasaan sholat berjamaah dengan kesadaran disiplin mengikuti aturan. Tujuan penelitian ini adalah: (1) untuk mengetahui kebiasaan melaksanakan shalat berjamaah siswa sehari-hari, (2) untuk mengetahui tingkat kedisiplinan siswa, dan (3) untuk mengetahui hubungan antara kebiasaan shalat berjamaah siswa terhadap sikap disiplin siswa.

Kebiasaan adalah suatu kegiatan yang dikerjakan dan akan berlangsung secara terus-menerus (Nur, 2011, hal. 18); merupakan cara bertindak yang diperoleh melalui belajar secara berulang-ulang, yang akhirnya menjadi menetap dan bersifat otomatis (Djaali, 2011, hal. 128) Sementara
Ulwan menjelaskan bahwa kebiasaan akan terbentuk melalui praktek nyata; Untuk itu membentuk kebiasaan perlu proses belajar, yang dalam pandangan behavioristik Ivan Pavlov dapat ditempuh melalui pengkondisian, menurut Thordike melalui latihan berulang-ulang, dan menurut Skinner melalui penguatan terhadap prilaku yang terbentuk dengan ganjaran dan hukuman (Erhamwilda, 2018, hal. 181184). Dengan demikian kebiasaan adalah suatu cara yang dipakai pendidik untuk membiasakan anak didik secara berulangulang, sehingga dengan sendirinya kebiasaan tersebut dapat dilakukan tanpa ada paksaan dari orang lain dan melakukannya dengan mudah, dengan senang hati secara terprogram maupun tidak.

Shalat berasal dari kata shola sholattan yang berarti doa atau permohonan berkah, doa dan orientasi kebaikan. Menurut istilah (ahli fikih) shalat sebagai kumpulan bacaan (ucapan), dan tingkah laku yang dibuka dengan takbir dan ditutup dengan salam disertai dengan persyaratanpersyaratan yang khusus (Sholikin, 2011, hal. 5-6). Shalat menurut bahasa berarti do'a (Hasan, 2000, hal. 19). Firman Allah Swt dalam QS At-Taubah ayat 103, artinya: "Dan do'akanlah untuk mereka. Sesungguhnya do'a kamu itu (menjadi) ketentraman jiwa bagi mereka, dan Allah Maha mendengar lagi Maha mengetahui (Q.S At-Taubah: 103) (Kemenag RI, 2016, hal. 314). Sedangkan menurut istilah shalat merupakan suatu ibadah yang mengandung perkataan dan perbuatan tertentu yang dimulai dengan takbir dan disudahi dengan salam (Ritonga, 1997, hal. 87). Menurut (Bahreisj, 1980, hal. 34) shalat menurut istilah bahasa arab berarti "doa", dalam pengertian syariat yaitu pemusatan seluruh pikiran dan hati menuju kepada Allah. Sedangkan jamaah berarti "berkelompok", "bersama-sama", atau dilakukan oleh 
banyak orang. Sehingga hal ini mengacu pada konsep kebersamaan umat Islam dalam berbagai persoalan kehidupan bermasyarakatnya (Sholikin, 2011, hal. 481). Adapun dalam firman Allah, yang artinya: "Dan berpeganglah pada tali Allah (dalam rengkuhan Al-Islam) dan janganlah kamu bercerai berai" (QS. Ali-Imran:103) (Kemenag RI, 2000, hal. 270).

Sedangkan shalat berjamaah adalah shalat yang dilakukan secara bersama-sama. Shalat dapat disebut shalat berjamaah jika dilakukan paling sedikit oleh dua orang, yaitu terdiri dari satu imam dan satu makmum (Zamani, 2016, hal. 119). Cara mengerjakan shalat berjamaah imam berdiri di depan dan makmum di belakang imam, makmum harus mengikuti setiap gerakan imam, dan tidak boleh mendahuluinya (Samsuri, 2002, hal. 49).

Jadi pengertian shalat berjamaah adalah suatu ibadah shalat yang dilakukan secara bersama-sama sesuai rukun dan syarat syah nya. Dapat dipahami bahwa kebiasaan shalat berjamaah adalah suatu kegiatan yang bersifat fisik atau non fisik dalam proses melakukan suatu ibadah shalat yang dilaksanakan secara bersamasama.

Rasulullah Saw bersabda yang artinya: "Shalat jamaabh lebih baik dua pulub tujuh derajat dibanding shalat sendirian" (H.R. Bukhari, no.645 dan Muslim, no.650). "Berikanlah kabar gembira bagi orang-orang yang berjalan ke masjid dalam kegelapan dengan cahaya yang sangat terang pada hari kiamat" (H.R. Abu Daud dan Tirmidzi, dishahihkan oleh Syaikh Albani).

Shalat berjamaah adalah sarana untuk melatih sebuah kedisiplinan waktu yang telah ditentukan dengan pasti, sehingga seseorang mampu melakukan shalat secara disiplin yang tinggi. Kemampuan untuk melakukan shalat berjamaah adalah sebuah jaminan bahwa orang tersebut, selain dapat dipercaya, juga memiliki kesadaran akan arti penting sebuah waktu yang harus ditepati (Ginanjar, 2007, hal. 212).

Shalat berjamaah termasuk sebab yang menjadikan seseorang melakukan shalat pada awal waktunya, termasuk amalan yang paling utama di sisi Allah (Bashori, 2016, hal. 45). Rasulullah Saw yang artinya: "Barangsiapa bersuci di rumahnya, lalu dia berjalan menuju masjid untuk menunaikan shalat, maka salah satu langkah kakinya akan menghapus dosa dan langkah kaki lainnya akan meninggikan derajatnya" (H.R. Muslim no.666).

Shalat itu sangat penting dalam menumbuhkan kedisiplinan, meningkatkan kehidupan itu sendiri ke dalam nilai spiritual, sehingga manusia akan memperoleh keseimbangan mental karena keyakinan tersebut (Haryanto, 2001, hal. 91).

Disiplin berarti latihan bathin dan watak yang, agar semua perbuatannya selalu mentaati tata tertib (Poerwodarminto, 1976, hal. 735). Kata disiplin, dalam bahasa Inggris discipline, berasal dari akar kata bahasa Latin yang sama (discipulus) dengan kata disciple dan mempunyai makna yang sama: mengajari atau mengikuti pemimpin yang dihormati. Pemimpin dimaksud meliputi orang tua, guru, maupun orang dewasa di lingkungan seseorang berada atau tunduk pada peraturan organisasi yang dimasuki ((Allen \& Cheryl, 2005, hal. 24); (Unaradjan, 2003, hal. 11); (Gie, 2002, hal. 90); (Djamarah, 2002, hal. 12)). Disiplin mempunyai dua pengertian, pertama bisa berarti pemeliharaan standar-standar tertentu atas suatu perbuatan melalui hukuman yang tepat. Kedua adalah pelatihan terhadap orang, sehingga mereka berperilaku sesuai dengan standar-standar tertentu (Wibisono, 2000, hal. 24). Dalam disiplin terdapat upaya pengendalian tingkah laku atau kontrol diri ((Imron, 2008, hal. 128); 
Marilyn E. Gootman dalam (Nizar, 2009, hal. 22); (Yaumi, 2016, hal. 92))

Perilaku disiplin ditunjukkan dengan upaya mengontrol sikap dan perilaku untuk berkomitmen dan konsisten melaksanakan aturan yang sudah ditetapkan orang yang memiliki otoritas ataupun Lembaga di mana individu berada sesuai dengan norma dan nilai yang dianut.

Perilaku disiplin akan bermanfaat bagi diri individu sendiri dan bagi orang lain atau masyarakat, agar individu menjadi manusia yang baik, warga negara yang baik, menciptakan suasana aman nyaman dan menyenangkan ((Shochib, 1998, hal. 3); (Unaradjan, 2003, hal. 19-20); (Mulyasa, 2007, hal. 26)). Bagi siswa perilaku disiplin sangat penting untuk mencegah perilaku menyimpang, mendorong melakukan yang benar, membantu menyesuiakan diri dengan tuntutan lingkungan, menjauhi yang dilarang, dan membentuk kebiasaankebiasaan yang baik dan bermanfaat (Susanto, 2018, hal. 122-123).

Dalam Islam kepatuhan untuk disiplin bukan hanya sekedar patuh pada aturan yang dibuat manusia tapi yang utama adalah patuh terhadap aturan yang ditetapkan Allah Swt sebagaimana dicontohkan oleh Rasulullah Saw. Seperti yang tercantum dalam firman Allah dalam Q.S. Al-Ahzab ayat 21 yang artinya:

"Sesunggubnya telab ada pada (diri) Rasulullah itu suri teladan yang baik bagimu (yaitu) bagi orang yang mengharap (rabmat) Allah dan (kedatangan) hari kiamat dan dia banyak menyebut Allab".

\section{METODE PENELITIAN}

Penelitian menggunakan pendekatan kuantitatif, metode deskriptif Angket dibuat dengan menggunakan jenis skala perilaku dan disusun oleh peneliti mengenai kebiasaan dengan jenis penelitian korelasional, mengacu pada Sugiyono, 2016, hal. 36. Penelitian ini dikategorikan penelitian korelasional karena menelaah hubungan antara satu variabel dengan variabel yang lain. Korelasi bertujuan untuk menemukan ada tidaknya hubungan antara dua variabel atau lebih.

Ada dua variable yang ingin dilihat hubungannya pada penelitian ini, yaitu:

1. Variabel bebas (X): Kebiasaan Shalat Berjamaah

2. Variabel terikat (Y): Disiplin

Populasi dalam penelitian adalah seluruh siswa kelas VIII di salah satu SMP Islam di Kota Bandung yang berjumlah sebanyak 294 siswa. Pengambilan populasi kelas VIII, karena masa studi siswa sudah lebih dari satu tahun sehingga pembiasaan sholat jamaah di sekolah juga sudah lebih 1 tahun. Sementara jika diambil di kelas 1, siswa masih dalam tahap penyesuaian terhadap aturan sekolah yang salah satunya adalah kewajiban melaksnakan sholat zuhur berjamaah. Kelas IX juga tidak dijadikan sampel, karena sedang mempersiapkan diri untuk ujian akhir sekolah. Sampel diambil dengan teknik pengambilan sampel secara rundom sampling, sampel diambil dari populasi yang berdistribusi normal. Untuk subjek penelitian homogen, maka sampel 100-200 sudah dipandang baik (Comrey, 1973, hal. 76), maka dalam penelitian ini diambil sampel $40 \%$ (117orang),

Instrumen penelitian menggunakan angket dengan skala Likert, untuk mengukur sikap, pendapat dan persepsi siswa tentang disiplin dan kebiasaan sholat berjamaah. Instrumen penelitian sebelum digunakan dilakukan judgment ahli.

shalat berjamaah dan sikap disiplin siswa, yang menyediakan lima alternatif jawaban yaitu SL (Selalu), SR (Sering), KK (Kadang- 
Kadang), JR (Jarang), TP (Tidak Pernah), setiap jawaban bernilai 1-5 sesuai dengan tingkat jawabannya.

Selain angket pengumpulan data dilengkapi dengan wawancara, dokumentasi, dan observasi terkait data siswa, sholat berjamaah di sekolah dan disiplin siswa di sekolah.

Instrumen penelitian diujikan dengan judgment ahli. Hasil perbaikan:

Hipotesis:

$\mathrm{H}_{1} \quad$ : Ada hubungan yang signifikan antara kebiasaan shalat berjamaah dengan sikap disiplin siswa.

$\mathrm{H}_{\mathrm{o}} \quad$ : Tidak ada hubungan yang signifikan antara kebiasaan shalat berjamaah dengan sikap disiplin siswa.

Teknik menganalisis data dengan melakukan uji statistik dengan rumus

\section{PEMBAHASAN}

Shalat berjamaah sangat berdampak terhadap disiplin seseorang, seperti disiplin terhadap aturan Allah, disiplin terhadap diri sendiri, disiplin terhadap peraturan di masyarakat, maupun disiplin terhadap waktu. Disiplin terhadap peraturan Allah seperti yang tercantum dalam firman Allah dalam Q.S. Al-Baqarah ayat 43 yang berbunyi:

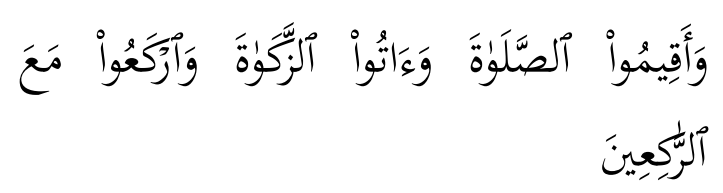

Artinya: "Dan dirikanlah shalat, tunaikanlah rakat dan rukuklab beserta orangorang yang rukuk".

Shalat berjamaah berdampak pada disiplin peraturan yang berlaku seperti yang tercantum dalam syarat sah shalat berjamaah, yaitu: tidak melampaui posisi imam dalam tempat shalatnya, tidak mendahului ucapan atau gerakan shalat korelasional product moment (Arikunto, 2002, hal. 168). Rumusnya adalah sebagai berikut:

$$
\mathrm{r}_{\mathrm{xy}}=\frac{\mathrm{n} \sum \mathrm{xy}-\left(\sum \mathrm{x}\right)\left(\sum \mathrm{y}\right)}{\sqrt{\left\{\mathrm{n} \sum \mathrm{x}^{2}-\left(\sum \mathrm{x}\right)^{2}\right\}\left\{\mathrm{n} \sum \mathrm{y}^{2}-\left(\sum \mathrm{y}\right)^{2}\right\}}}
$$

Keterangan:

$\mathrm{r}_{\mathrm{xy}}$ : koefisien korelasi antara variabel $\mathrm{x}$ dengan variabel y

$\mathrm{n}$ : jumlah responden

$\Sigma x$ jumlah skor setiap butir soal

$\sum y$ : jumlah skor total

$\sum \mathrm{x}^{2}$ : jumlah kuadrat skor butir

$\Sigma y^{2}$ : jumlah kuadrat skor total

$\sum x y$ : jumlah perkalian skor butir dengan skor total

Sebelum melakukan uji korelasi antara dua variabel dilakukan penghitungan Mean, median, modus, SD, uji normalitas data, serta uji validitas data.

imam, dan shalat yang dikerjakan oleh makmum harus sama dengan shalat yang dikerjakan oleh imam (Sutrisno, 2016, hal. 85). Berdasarkan sabda Rasul dari Malik Ibnu Al-Huwairts yang artinya: "Shalatlah kalian sebagaimana kalian melihat aku shalat" (H.R. Al-Bukhari no.628, dan Muslim no.1533). Salah satu manfaat shalat berjamaah adalah untuk belajar disiplin dan mengendalikan jiwa, caranya adalah dengan selalu mengikuti imam dalam setiap takbir atau gerakannya di dalam shalat, tidak mendahului atau memperlambat diri darinya, bersamaan atau berlomba-lomba dengannya (Musbikin, 2007, hal. 51). Seseorang dapat memiliki kedisiplinan dalam hal berperilaku baik dengan rajin melaksanakan shalat berjamaah, hal ini sebagaimana yang terdapat dalam firman Allah dalam Q.S. Al-Ankabut ayat 45 yang artinya: "Bacalab apa yang telab diwabyukan kepadamu, yaitu Al-Qur'an dan dirikanlah shalat. Sesunggubnya shalat itu mencegab dari perbuatan keji dan munkar, dan sesunggubnya mengingat Allah (shalat) adalah lebih besar 
(keutamaannya dari ibadah-ibadah yang lain), dan Allab mengetahui apa yang kamu kerjakan”.

Pelaksanaan ajaran Islam secara teratur dapat memberikan dampak positif bagi perilaku sehari-hari, misalnya semakin rajin dan tertib seorang muslim dalam mengerjakan ibadah shalat, maka akan semakin rajin dan tertib pula seseorang dalam mengerjakan suatu pekerjaan yang lain. Kedisiplinan dalam mengerjakan suatu pekerjaaan membuat seseorang tidak akan membebani orang lain untuk mengerjakan pekerjaan yang menjadi kewajibannya, dan akan memberi manfaat kepada lingkungannya dengan produktivitas dan kinerjanya yang tertib, teratur.

Seseorang yang rajin dan tertib dalam menjalankan shalat secara berjamaah dapat menunjang keberhasilan pelaksanaan kedisiplinan sebagai seorang muslim. Keberhasilan menjalankan shalat berjamaah yang tertib dan teratur dapat berpengaruh pada kedisiplinan seseorang dalam melakukan suatu pekerjaan. Semakin baik ibadah shalat seseorang, akan semakin baik tingkat kedisiplinannya. Sebaliknya semakin sering seseorang mengabaikan aspek ibadah terutama shalat, maka akan lebih mudah pula mengabaikan urusan di luar ibadah. Dengan demikian setiap siswa yang aktif melaksanakan shalat berjamaah, akan berpengaruh terhadap kedisiplinan, hal itu berarti semakin terbiasa siswa dalam melaksanakan shalat berjamaah, akan semakin baik pula kedisiplinannya.

Pengamalan ibadah shalat berjamaah akan memberikan pengaruh terhadap disiplin siswa, karena sikap taat, jujur, sungguh-sungguh, dan ketepatan shalat pada waktunya akan menjadi bagian dari kepribadian orang yang melakukan shalat berjamaah, hal itu juga akan mendorongnya selalu aktif, rajin, dan disiplin diri dalam kehidupan sehari-hari. Menurut (Ginanjar, 2007, hal. 212) shalat berjamaah sarana untuk melatih sebuah kedisiplinan waktu yang telah ditentukan dengan pasti, sehingga seseorang mampu melakukan shalat secara disiplin. Kemampuan untuk melakukan shalat berjamaah adalah sebuah jaminan bahwa orang tersebut, selain dapat dipercaya, juga memiliki kesadaran akan arti penting sebuah waktu yang harus ditepati. Hubungan kebiasaan shalat berjamaah dengan sikap disiplin sangat erat sekali, terutama dalam disiplin waktu, karena waktu adalah kunci kesuksesan yaitu apabila seseorang dapat menggunakan waktunya dengan baik. Seperti yang tercantum dalam firman Allah dalam Q.S. Al-Asr ayat 1-3 yang berbunyi:

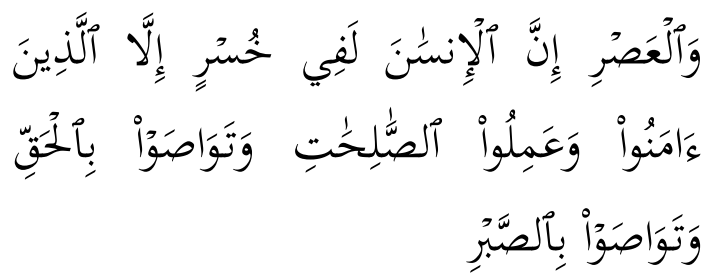

Artinya: "Demi masa. Sesungguhnya manusia itu benar-benar dalam kerugian, kecuali orang-orang yang beriman dan mengerjakan amal saleh dan nasehat menasehati, supaya mentaati kebenaran dan nasehat menasehati supaya menetapi kesabaran".

\section{KESIMPULAN}

Berdasarkan uji korelasi ditemukan kebiasaan shalat berjamaah dan sikap disiplin siswa tergolong kategori tinggi, terdapat hubungan yang positif dan signifikan antara kebiasaan shalat berjamaah dengan sikap disiplin siswa. Siswa yang terbiasa melaksanakan shalat berjamaah memiliki sikap disiplin yang baik di manapun mereka berada, meskipun tidak ada peraturan yang mengikat di dalamnya. Sedangkan siswa yang tidak terbiasa melaksanakan shalat berjamaah, mereka memiliki sikap disiplin yang kurang 
baik dalam kehidupan sehari-harinya. Semakin tinggi kebiasaan shalat berjamaah, maka semakin tinggi tingkat disiplin siswanya. Begitu pula sebaliknya, semakin rendah kebiasaan shalat berjamaah, maka semakin rendah pula tingkat disiplin siswa di dalam kehidupan sehari-harinya. Berdasarkan temuan ini, bagi sekolahsekolah yang mayoritasnya beragama Islam dapat mengupayakan menyelenggarakan kebiasaan sholat berjamaah di sekolah, terutama sholat fardhu, sekaligus berfungsi mengembangkan karakter disiplin siswa.

\section{DAFTAR PUSTAKA}

Allen, J. E., \& Cheryl, M. (2005). Disiplin Positif (I. Machfud, ed.). Jakarta: Tim Prestasi Pustakarya.

Arikunto, S. (2002). Prosedur Penelitian Suatu Pendekatan Praktek. Jakarta: PT Rineka Cipta.

Bahreisj, H. (1980). Pedoman Fiqih Islam. Surabaya: Al-Ikhlas.

Bashori, M. (2016). Dahsyatnya Istiqamah Shalat Berjamaah. Yogyakarta: Semesta Hikmah.

Comrey, A. . (1973). A First Course in Factor Analysis. New York: NY Academic Press.

Djaali. (2011). Psikologi Pendidikan. Jakarta: PT Bumi Aksara.

Djamarah, S. B. (2002). Prestasi Belajar dan Kompetensi Guru. Jakarta: Rineka Cipta.

Erhamwilda. (2018). Psikologi Belajar Islami. Jokyakarta: Psikosain.

Gie, T. L. (2002). Cara Belajar Yang Efisien. Yogyakarta: Liberti Yogyakarta.

Ginanjar, A. A. (2007). Rahasiah Sukses Membangun Kecerdasan Emosi dan
Spiritual ESQ: Emosional Spiritual Quotient Berdasarkan 6 Rukun Iman dan 5 Rukun Islam. Jakarta: Penerbit Arga.

Haryanto, S. (2001). Psikologi Shalat. Yogyakarta: Mitra Pustaka.

Haryanto, S. (2009). Psikologi Shalat. Yogyakarta: Mitra Pustaka.

Hasan, A. (2000). Studi Al-Qur'an dan Sunnah. Jakarta: Raja Grafindo Persada.

Imron, A. (2008). Pembinaan Guru di Indonesia. Jakarta: Pustaka Jaya.

Kemenag RI. (2000). Al-Qur'an dan Terjemahnya. Bandung: CV Diponegoro.

Kemenag RI. (2016). Al-Qur'an dan Terjemahnya. Bandung: PT Mutiara Qalbu Salim.

Masyhur, K. (1995). Shalat Wajib Menurut Madŗbab yang Empat). Jakarta: Rineka Cipta.

Mulyasa. (2007). Manajemen Pendidikan Karakter. Jakarta: Bumi Aksara.

Musbikin, I. (2007). Misteri Shalat Berjamaah Bagi Kesehatan Fisik dan Fsikis. Yogyakarta: Mitra Pustaka.

Nizar, I. A. I. (2009). Membentuk dan Meningkatkan Disiplin Anak Sejak Dini. Yogyakarta: Diva Press.

Nur. (2011). Kamus Besar Bahasa Indonesia. Jakarta: Balai Pustaka.

Poerwodarminto. (1976). Kamus Umum Bahasa Indonesia. Jakarta: Balai Pustaka.

Raya, Thib, A., \& Mulia, S. M. (2003). Menyelami Seluk Beluk Ibadah dalam Islam. Jakarta: Kencana.

Ritonga, H. (1997). Pengembangan Disiplin. 
Anne Andriane, Erhamwilda / Ta'dib: Jurnal Pendidikan Islam, Vol. 9 No. 1 (2020) 42-50

ISSN 1411-8173 | E-ISSN 2528-5092

https:/ / ejournal.unisba.ac.id/index.php/tadib/article/view/6207

Samsuri. (2002). No Title.

Shochib, M. (1998). Pola Asub Orang Tua Dalam Membantu Anak Mengembangkan Disiplin Diri. Jakarta: PT Rineka Cipta.

Sholikin, M. (2011). The Miracle of Shalat (Mengungkap Kedabsyatan Energi Shalat). Jakarta: Erlangga.

Sugiyono. (2016). Metode Penelitian Kuantitatif, Kualitatif, dan R\&D. Bandung: Alfabeta.

Susanto, A. (2018). Teori Belajar dan Pembelajaran di Sekolah Dasar. Jakarta: Kencana Prenadamedia
Group.

Sutrisno, H. (2016). Metodologi Research. Yogyakarta: ANDI Offset.

Unaradjan, D. (2003). Manajemen Disiplin. Jakarta: PT Grasindo.

Wibisono, D. (2000). Manajemen Kinerja. Jakarta: Erlangga.

Yaumi. (2016). Pendidikan Karakter dan Landasan. Jakarta: Prenadamedia Group.

Zamani, Z. (2016). Shalatlah Kamu Sebelum Dishalatkan. Yogyakarta: Sketsa. 